\title{
The microstructure in the placenta is influenced by the functional diversity of HLA-G allelic variants
}

\author{
F. Stieglitz ${ }^{1}$ - A. A. Celik ${ }^{1}$ - C. von Kaisenberg ${ }^{2} \cdot$ M. A. Camps ${ }^{3} \cdot$ R. Blasczyk $^{1} \cdot$ Christina Bade-Döding $^{1}$
}

Received: 21 March 2019 / Accepted: 31 May 2019 / Published online: 27 June 2019

(C) The Author(s) 2019

\begin{abstract}
The main expression sites of HLA-G are human extravillous trophoblast cells. The interaction of HLA-G with uterine NK cells promotes their maturation and differentiation into decidual NK $(\mathrm{dNK})$ cells. dNK cells secrete chemokines, cytokines, and proangiogenic factors in favor of a vascular remodeling and an immune suppressive microenvironment of the decidua. HLA$\mathrm{G}$ is the most polymorphic member of the oligomorphic non-classical HLA molecule family; yet, the impact of polymorphic differences is not comprehensively understood. sHLA-G levels in embryo culture medium correlate with successful pregnancy; however, it remains questionable if HLA-G allelic diversity impacts on the outcome of dNK cell development. We utilized synthetic $S H L A-G^{*} 01: 01,01: 03$, and 01:04 molecules and transduced $K 652 / m H L A-G^{*} 01: 01,01: 03$, and 01:04 cells to study the biological interaction between HLA-G alleles and primary NK cells of human term placenta. Despite its low frequency, HLA$G^{*}$ 01:04 and not the most prevalent allele $H L A-G^{*} 01: 01$ appear to be strong catalysts of dNK cell proliferation. Concluding, this study illustrates novel insights into the impact and binding efficiency of the three most common variants of HLA-G on primary placental NK cells.
\end{abstract}

Keywords dNK cells $\cdot$ HLA-G $\cdot$ Placenta $\cdot$ Development $\cdot$ Decidua $\cdot$ Pregnancy

\section{Introduction}

HLA-G, a non-classical HLA-I molecule, features specialized abilities to confer immune protection by, e.g., suppressing the immune system, promoting vascularization of the decidua, and promoting tolerance induction of the maternal immune system towards the fetus. Due to its oligomorphic nature, HLA-G has only 58 allotypes (Robinson et al. 2014) with HLA-G*01:01 predominantly expressed followed by $G^{* 01: 03}$ and $G^{*} 01: 04$. The most recent study revealed that

Electronic supplementary material The online version of this article (https://doi.org/10.1007/s00251-019-01121-0) contains supplementary material, which is available to authorized users.

Christina Bade-Döding

bade-doeding.christina@mh-hannover.de

1 Hannover Medical School, Institute for Transfusion Medicine, Carl-Neuberg-Str. 1, 30625 Hannover, Germany

2 Department of Obstetrics and Gynecology, Hannover Medical School, Carl-Neuberg-Str. 1, 30625 Hannover, Germany

3 Imusyn GmbH \& Co. KG, Feodor-Lynen-Str. 5, 30625 Hannover, Germany those alleles differ highly in their presented peptide repertoire and their mediated protection against NK cell-mediated lysis (Celik et al. 2018a). Few polymorphic variants and their variability in the presented peptide repertoire and allele-specific interaction with NK cells have been described (Celik et al. 2018a). Findings that the sHLA-G level in embryo culture medium correlates with successful pregnancy underline the major importance of HLA-G during gestation (Lynge Nilsson et al. 2014). Considering the significant role of HLA-G in successful pregnancies, the HLA-G allele-specific manipulation of pNK cell function, and the observation that the interaction between HLA-G and its interaction with decidual NK cells (dNK) appears to be vital for implantation, subsidization, and tolerance of the fetus, there might be a potential impact of allelic HLA-G variants. Pregnancies are outstanding events that resemble a substantial challenge to the maternal immune system. The fetus represents a semiallogeneic transplant that has to be protected from rejection by the mother. Under healthy physiological conditions, the placental extravillous trophoblasts (EVTs) are the main expressing site of HLA-G1 and HLA-G5 (Fournel et al. 2000; Juch et al. 2012). Several membrane-bound (G1-G4) and soluble (G5G7) isoforms that are varying in the composition of their $\alpha$ 
subunits exist and are generated by alternative splicing. Although for those isoforms receptors are suggested, it remains unclear whether they have a significant function in vivo (Toni Ho et al. 2018). During the process of implantation, fetal trophoblast cells invade the maternal decidua and the spiral arteries, creating large vessels with a lower resistance for the circulating maternal blood; this increases the blood stream to the fetus (Lyall et al. 2001).

dNK cells play a pivotal role in the process of trophoblast invasion. Peripheral NK (pNK) cells represent $<15 \%$ of the lymphocyte population (Timonen and Ortaldo 1981), while the NK cell population of the decidua basalis represents approximately $70 \%$ of lymphocytes in the early stage of pregnancy (King et al. 1989; Moffett-King 2002). The main task for pNK cells is to kill maligned and virus-infected cells (Jost and Altfeld 2013); in contrast to that, dNK cells lost their cytotoxic abilities under healthy conditions completely (Kopcow et al. 2005) and further promoting an immunosuppressive status by stimulating the production and release of indoleamine 2,3-dioxygenase (IDO) by $\mathrm{dCD} 14^{+}$cells leading to the induction of Tregs (Vacca et al. 2010). Noteworthy, KIR (KIR3DL1, KIR3DL2, KIR2DL3, and KIR2DL4) receptors are significantly upregulated in dNK cells compared with pNK cells; interestingly, the KIR2DL4 receptor is only present in dNK cells, indicating an adaptation to the presence of HLA-G (Koopman et al. 2003). Moreover, dNK cells promote decidual vascularization and concentrate nearby the spiral arteries while releasing MMPs that lead to the maceration of extracellular matrix of the vascular smooth muscle cells. This process promotes the vascular remodeling that is vital for the supplementation of the fetus (Hazan et al. 2010; Robson et al. 2012; Smith et al. 2009). To conclude, dNK cells distinguish significantly from pNK cells in terms of cytotoxicity, release of cytokines and chemokines, their immune modulatory properties, and their promoting of vascular growth (Le Bouteiller 2013). Notably, low quantities of dNK cells are highly associated with recurrent spontaneous abortions (Quack et al. 2001).

The origin and development of dNK cells is still not comprehensively investigated, yet two theories attempt to explain their origin (Jabrane-Ferrat and Siewiera 2014). One theory describes that dNK cells are derived from local progenitor cells or immature uterine NK ( $\mathrm{uNK}$ ) cells. This theory is based on the observation that dNK cells could be developed from progenitor cells in situ by a certain chemokine/cytokine and hormone cocktail (Kane et al. 2009; Vacca et al. 2011). Furthermore, local immature uNK cells could be found in the uterus and regulate the development cycle of the endometrium during the menstruation cycle and their count shifts along with the IL-15 concentration. CD $34^{+}$NK lineage precursor cells that could be detected in the uterus differentiate to dNK cells in the presence of IL-15 (Bilinski et al. 2008; Manaster and Mandelboim 2008).
The second theory assumes that CD56 $6^{\text {bright }} \mathrm{pNK}$ cells migrate from the periphery into the decidua where they are reeducated and develop into dNK cells in the decidual microenvironment (Jabrane-Ferrat and Siewiera 2014). This theory is supported by the observation that EVT cells produce large amounts of NK-specific chemokines and that pNK cells could be primed to develop a dNK phenotype utilizing TGF- $\beta$ or IL15 (Carlino et al. 2008; Cerdeira et al. 2013; Drake et al. 2001; Hanna et al. 2003; Kunkel and Butcher 2002).

In the last decade, HLA-G emerged as an additional key factor for dNK cell development and maintenance of the dNK cell status and continuous proliferation. It could be demonstrated that uNK cells begin to proliferate and secrete INF- $\gamma$ and VEGF during co-incubation with cells expressing transduced membrane-bound HLA-G (mHLA-G). This experiment was performed with human uNK cells before conception, indicating that the contact of uNK cells with mHLA-G on EVTs could lead to the maturation of uNK cells to dNK cells. dNK cells promote vascularization and decidualization of the implantation site; this effect was not seen when the whole uterine mononuclear cell population (UMC) was incubated with mHLA-G expressing cells (van der Meer et al. 2004). Besides, it could be demonstrated that the acquirement of mHLA-G from the cell surface of EVTs via trogocytosis by dNK cells is essential for maintaining their low-level cytotoxicity (Tilburgs et al. 2015).

In the light of recent attempts to generate dNK cells in vitro (Cerdeira et al. 2013) with the overall aim to treat reproductive disorders, the importance of understanding the impact of HLA-G subtypes on the maintenance and development of the $\mathrm{dNK}$ cell population becomes obvious.

\section{Material and methods}

\section{Cell lines}

All cell lines were maintained at $37{ }^{\circ} \mathrm{C}$ and $5 \% \mathrm{CO}_{2}$. HLA class I negative $K 562$ cells transduced with HLA-G*01:0x (exons 1-6) (Celik et al. 2018a) or sHLA-G*01:0x (soluble, exons 1-4) (Celik et al. 2018a; Celik et al. 2018b), and NK cell cultures were maintained in RPMI1640 (Lonza, Basel, Switzerland) supplemented with $10 \%$ heat-inactivated FCS (Lonza, Basel, Switzerland), 2 mM L-glutamine (c. c. pro, Oberdorla, Germany), $100 \mathrm{U} / \mathrm{mL}$ penicillin and $100 \mu \mathrm{g} / \mathrm{mL}$ streptomycin (c. c. pro, Oberdorla, Germany), and $1.8 \times$ $10^{3} \mathrm{U} / \mathrm{mL}$ ProLeukinS ${ }^{\circledR}$ (Novartis, Basel, Switzerland).

$H E K 293 T$ cells, used for production of lentiviral particles, were cultured in DMEM (Lonza, Basel, Switzerland) supplemented with $10 \%$ heat-inactivated FCS, 2 mM L-glutamine, $100 \mathrm{U} / \mathrm{mL}$ penicillin, $100 \mu \mathrm{g} / \mathrm{mL}$ streptomycin, and $1 \mathrm{mg} / \mathrm{mL}$ Geneticin ${ }^{\circledR}$ (Life Technologies, Carlsbad, USA). All cell lines were maintained at $37{ }^{\circ} \mathrm{C}$ and $5 \% \mathrm{CO}_{2}$. 


\section{Isolating NK cells from term placental tissue}

dNK were isolated from a whole human placenta. Human term placenta was obtained from the cesarean section at the term of pregnancy. The obtained term placentas weigh about $750-1250 \mathrm{~g} ; 250 \mathrm{~mL}$ PBS containing $50 \mathrm{U} / \mathrm{mL} \mathrm{Na} /$ heparin was added immediately after cesarean section to the placenta at RT. Subsequently, the placenta was minced with sterile-disposable scalpels into $2 \times 2 \mathrm{~cm}$ large pieces. Those pieces were transferred to a petri dish, crumpled with the hard end of a $60-\mathrm{mL}$ syringe plunger, and then rinsed with $5 \mathrm{~mL}$ PBS/heparin solution; the tissue was discarded, and the flow through was collected. After processing the whole placental tissue, the flow through was centrifuged at $422 \times g$ for $10 \mathrm{~min}$; the resulting pellets were pooled in $25 \mathrm{~mL}$ PBS and separated twice by density gradient centrifugation utilizing Lymphosep ${ }^{\mathrm{TM}}$ medium. Between the isolation steps, the collected lymphocytes were washed once with $25 \mathrm{~mL}$ PBS $(270 \times \mathrm{g}, 10 \mathrm{~min})$ to remove uptaken Lymphosep ${ }^{\mathrm{TM}}$ medium (MP Biomedicals, LLC, OH, USA). After density separation, cells were washed twice with $25 \mathrm{~mL}$ PBS $(270 \times \mathrm{g}, 10 \mathrm{~min}$; $187 \mathrm{~g}, 10 \mathrm{~min}$ ). Finally, cells were resuspended in $10-\mathrm{mL}$ placenta medium per $1 \times 10^{8}$ cells. Isolation of $\mathrm{CD} 56^{+}$from isolated placental cells has been performed using the EasySep $^{\mathrm{TM}}$ Human NK Cell Enrichment Kit (Stemcell Technologies, Vancouver, Canada).

\section{HLA-G genotyping}

To determine the HLA-G alleles of the utilized placenta, donor DNA was isolated utilizing the NucleoSpin ${ }^{\circledR}$ Blood kit (Macherey-Nagel, Düren, Germany). Specific primers were used to generate the required parts (Fig. 1) of the donor DNA for genotyping (Table 1). PCR solution contains $1.25 \mu \mathrm{L}$ forward and reverse primer (2.5), $2 \mu \mathrm{L}$ DNA, $5 \mu \mathrm{L}$ betaine $(5 \mathrm{M}), 12.5 \mu \mathrm{L}$ Bio-X-Act, and $3 \mu \mathrm{L} \mathrm{H}_{2} 0$. Total volume was $25 \mu \mathrm{L}$. Following amplification, the PCR products were purified using EXOSAP-IT (Thermo Fisher Scientific, Waltham, USA) and subjected to Sanger sequencing. Sequence analysis was performed by HiType (Inno-Train Diagnostics, Kronberg, Germany) using the most recent HLA database release.
Table 1 Primer for HLA-G genotyping

\begin{tabular}{lll}
\hline Name & Direction & Sequence \\
\hline HLA-G_A_f_in1 (FWD) & Forward & 5'-tctaaagtcctcgctcacc-3' \\
HLA-G_A_r_in3 (REV) & Reverse & 5'-cttgtgctaggccaggc-3' \\
HLA-G_E_f_in2 (FWD) & Forward & 5'-cctcttcctgctgctctc-3' \\
HLA-G_C_fin3 (FWD) & Forward & 5'-gtcacatccaggtgctg-3' \\
HLA-G_C_r_in5 (REV) & Reverse & 5'-agtgggacaagaaaactcagac-3' \\
\hline
\end{tabular}

\section{Production of transduced K562 cells expressing sHLA-G or mHLA-G molecules}

Transduced K562 cells expressing $S H L A-G^{*} 01: 01,01: 03$, or 01:04 have been cultured; sHLA-G*01:0x molecules have been isolated as previously described (Celik et al. 2018a), and transduced $K 562$ cells expressing $m H L A-G^{*} 01: 01$, 01:03, or 01:04 have been sorted for 100\% $m H L A-G^{*} 01: 0 x$ surface expression as described (Celik et al. 2018a).

\section{dNK cell proliferation assay}

To determine the influence of the HLA-G variants on proliferation of decidual NK cells, a proliferation assay was performed as described by van der Meer et al. (2004), with the modification that CFSE dilution was utilized for measuring proliferation. NK cells were labeled with CFSE and plated at $5 \times 10^{4}$ cells/well in triplicates in 96-well U-bottom microtiter plates in the presence of irradiated ( 30 Gy) K562 or transduced mHLA-G*01/0x expressing $K 562$ cells $\left(5 \times 10^{4}\right.$ cells/well) in a total volume of $200 \mu \mathrm{L}$. Medium exchange was performed every 3 days. Proliferation analysis was performed at day 6 measuring CFSE dilution of $\mathrm{CD} 56^{+}$cells.

\section{sHLA-G-CD56 ${ }^{+} / \mathrm{CD}^{+}$NK cell binding assay}

To determine binding potential and variability of the three allelic subtypes, $s H L A-G^{*} 01: 01,01: 03$, or 01:04, to bind to dNK cells, $5 \times 10^{6} \mathrm{dNK}$ cells have been stained for $4 \mathrm{~h}$ with purified transduced C-terminally V5-tagged sHLA-G*01:0x molecules at a concentration of $30 \mu \mathrm{g} / \mathrm{mL}$. Binding was

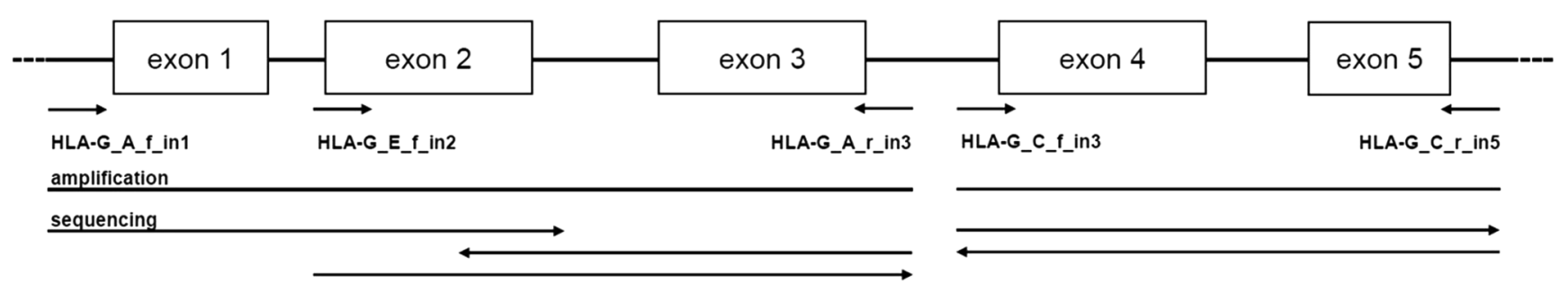

Fig. 1 Location of HLA-G primers for amplification and sequencing 
detected using $5 \mu \mathrm{L}$ anti-V5 (clone MCA1360) (Bio-Rad Laboratories, Inc., Hercules, USA) and goat anti-mouse PE (BD Biosciences, Heidelberg, Germany). Following incubation, $5 \mu \mathrm{L}$ anti-CD9 FITC (clone eBioSN4) (Life Technologies $^{\mathrm{TM}}$, Carlsbad, USA) and $5 \mu \mathrm{L}$ anti-human CD56-APC (clone NCAM16.2) (BD Biosciences, Heidelberg, Germany) were added to stain the dNK cells. Cell populations were analyzed by flow cytometry.

\section{Statistical analyses}

For statistical analyses of the proliferation data, a one-way ANOVA and Tukey's multiple comparison test were utilized.

\section{Ethical approval}

Written informed consent was obtained from the patients to donate the placenta to research; ethical committee approval had been obtained (MHH Research Obstetrics Biobank No. 1303-2012).

\section{Results}

\section{sHLA-G*01:0x binding to CD56 ${ }^{+ \text {bright }} / \mathrm{CD}^{+}$NK cells}

To examine the binding efficiency of the three most common HLA-G alleles $\left(\mathrm{G}^{*} 01: 01, \mathrm{G}^{*} 01: 03, \mathrm{G}^{*} 01: 04\right)$ to primary dNK cells, purified sHLA-G*01:0x variants were incubated with isolated lymphocytes from human term placenta. It could be observed that $s H L A-G * 01: 01$ and SHLA- $G^{*} 01: 04$ bind with an overall higher efficiency to the $\mathrm{CD}^{2} 6^{\text {+bright }} / \mathrm{CD}^{+}$dNK subset than $s H L A-G^{*} 01: 03$ (01:01 58.4\%; 01:03 10.4\%; 01:04 65.9\%) (Fig. 2). The sHLA-G binding to CD $56^{+ \text {bright }} / \mathrm{CD}^{+} \mathrm{NK}$ cells from the same batch varied between $17.8 \%$ for $01: 01,1.5 \%$ for 01:03, and 20.6\% for 01:04 (Suppl. Fig. 1).

\section{Proliferation assay of primary NK cells from placental tissue}

The HLA-deficient cell line $K 562$ was transduced with lentiviral vectors encoding for $m H L A-G^{*} 01: 01$, mHLA$G^{*}$ 01:03, or $m H L A-G^{*} 01: 04$ and subsequently sorted for

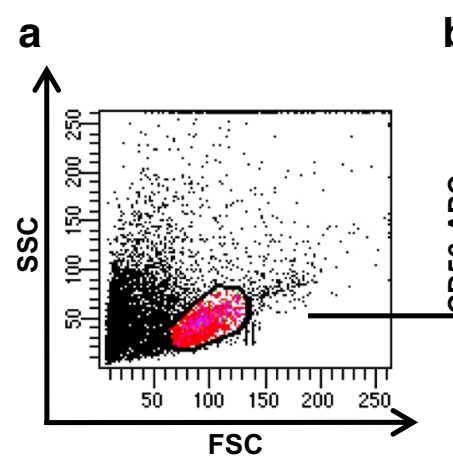

b

d
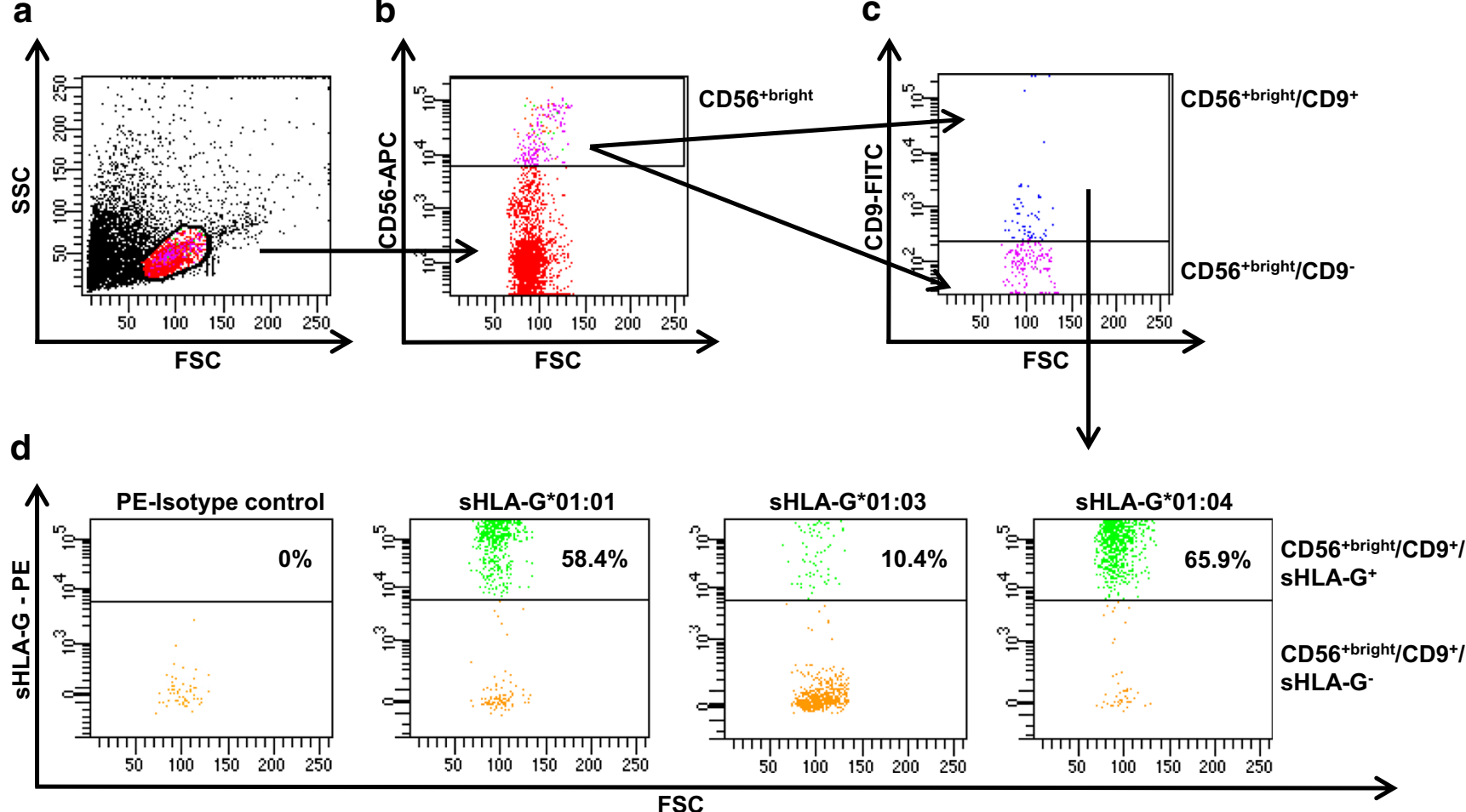

Fig. 2 Binding of dNK cells to SHLA-G*01:01, 01:03, or 01:04. Gating strategy $(\mathbf{a}-\mathbf{c})$ and analysis of sHLA-G binding to $\mathrm{CD} 56^{\text {bright }} / \mathrm{CD}^{+}$ cells. d sHLA-G*01:01 and saHLA-G*01:04 bind with an overall higher

efficiency to the $\mathrm{CD} 56^{\text {+bright }} / \mathrm{CD}^{+}$subset than sHLA-G*01:03. The HLA-G genotype of the represented donor was HLA-G*01:01 
$100 \%$ of the respective $\mathrm{mHLA}-\mathrm{G}$ expression. Untouched primary $\mathrm{CD} 56^{+} \mathrm{NK}$ cells were recovered from human term placenta, stained with CFSE, and co-incubated with the transduced K562 cells expressing HLA-G for 6 days. Proliferation of NK cells was monitored by CSFE dilution (Fig. 3a). Primary dNK cells incubated with K562 cells showed $12 \%$ proliferation after 6 days. dNK cells that were incubated with mHLA-G*01:04 expressing K562 cells showed the highest proliferation rate with $\sim 50 \%$; NK cells co-incubated with $m H L A-G^{*} 01: 01$ or $m H L A-$ $G^{*} 01: 03$ expressing $K 562$ cells had a substantially lower proliferation rate $\left(H L A-G^{*} 01: 01 \sim 30 \%\right.$; HLA-G*01:03 $7 \%)$. The proliferation levels of non-dNK cells from the same batch varied from $\sim 12 \%$ for $01: 01, \sim 4 \%$ for $01: 03$, and $\sim 13 \%$ for 01:04 (Suppl. Fig. 2). This experiment was performed with three different donors varying in their genotype (donor A HLA-G*01:01/01:05N; donor B HLA$G^{*} 01: 01 / 01: 01$; donor C HLA-G*01:01/01:04:02).
A significant increase in proliferation could be detected when primary NK cells were incubated with $\mathrm{K5} 62 / \mathrm{mHLA}$ $G^{*}$ 01:04 cells in comparison with $K 562$ cells or $\mathrm{K562/}$ $m H L A-G^{*} 01: 03$ cells, respectively $(p=0.0002 ; p<0.0001)$. Furthermore, a significant difference could be detected between K562/mHLA-G*01:01 and K562/mHLA-G*01:03 and between K562/mHLA-G*01:01 and K562/mHLA-G*01:04 $(p=0.0295 ; p=0.0033)$ (Fig. 3b).

\section{Discussion}

The immunosuppressive abilities of HLA-G have been extensively studied and recognized in recent years. HLA-G is the most polymorphic representative of the oligomorphic HLA-Ib molecules; however, little is known about the differential impact of the most prevalent allelic variants $H L A-G^{*} 01: 01$, $H L A-G^{*} 01: 03$, and $H L A-G^{*} 01: 04$. We recently identified a

a

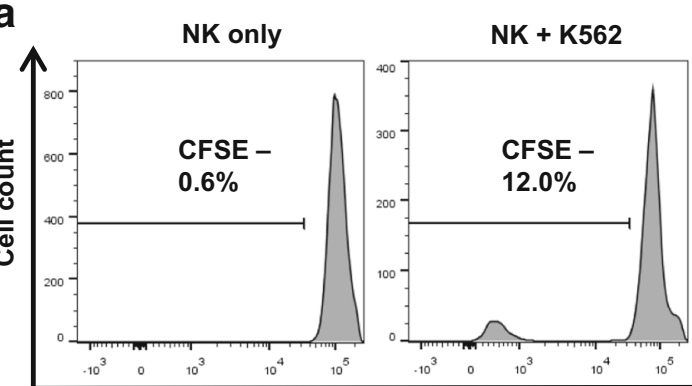
$\mathrm{NK}+\mathrm{K} 562 / \mathrm{mHLA}-\mathrm{G}^{*} 01: 01 \mathrm{NK}+\mathrm{K} 562 / \mathrm{mHLA}-\mathrm{G} * 01: 03 \mathrm{NK}+\mathrm{K} 562 / \mathrm{mHLA}-\mathrm{G}$ 01:04

b

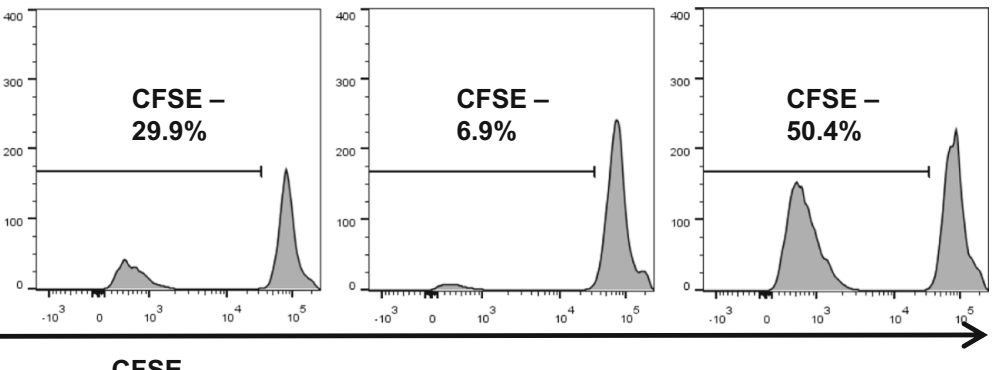

CFSE

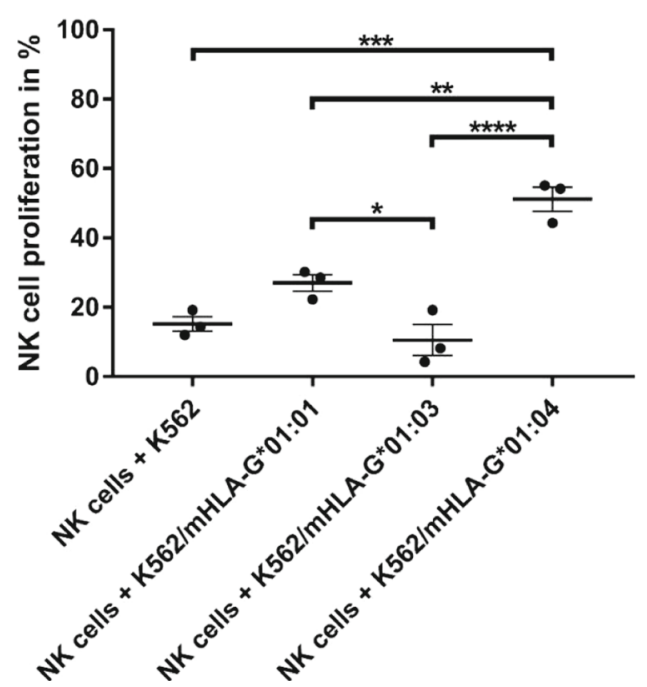

Fig. 3 Proliferation of primary dNK cells from human term placenta after exposure to different HLA-G allelic variants. Analysis of proliferation of primary dNK cells from human term placenta after co-incubation with HLA-G* 01:01, 01:03, or 01:04 expressing K562 cells (a). Stimulation of proliferation could be unambiguously attributed to HLA-G*01:04. A significant difference in terms of proliferation activation could be detected between mHLA-G*01:01 and mHLA-G*01:03 and between mHLA$\mathrm{G}^{*} 01: 01$ and mHLA-G*01:04 $(p<0.05 ; p<0.005)(\mathbf{b})$. **** $p$ value $<$ $0.0001 ; * * * p$ value $<0.0005 ; * * p$ value $<0.005 ; * p$ value $<0.05$ 
remarkable difference between these variants in terms of the presented peptide repertoire and their capability of inhibiting NK cell-mediated lysis, whereby $H L A-G^{*} 01: 04$ has been found to convey the most protective status for NK cellmediated lysis (Celik et al. 2018a). The main function of HLA-G in vivo is to convey an immunotolerant status to the fetus and promote vascularization of the decidua as well as promoting the implantation of the zygote (Ferreira et al. 2017). Therefore, this study concentrated on the functional differences of the most common HLA-G variants and their allelic impact on the proliferation of primary dNK cells from human term placenta.

To analyze binding efficiency and variability of HLA-G variants to primary lymphocytes from human term placenta, the allelic subtypes $H L A-G^{*} 01: 01,01: 03$, or 01:04 were engineered with a $\mathrm{C}$-terminal V5 tag to enable the detection of binding to the subset of primary dNK cells. Notably, $S H L A-$ $G^{*} 01: 04$ and $s H L A-G^{*} 01: 01$ bound with an efficiency of $65.9 \%$ and $58.4 \%$, respectively, whereas $S H L A-G^{*} 01: 03$ featured only $10.4 \%$ binding efficiency (Fig. 1). Interestingly, Celik et al. (2018) previously described $m H L A-G^{*} 01: 04$ to convey the strongest protection against NK cell-mediated lysis (Celik et al. 2018a). This data stands in coherency with the highest binding efficiency observed with $s H L A-G^{*} 01: 04$ in comparison with the other allelic variants in this study. Furthermore, no major functional difference between $H L A$ $G^{*} 01: 01$ and $H L A-G^{*} 01: 03$ in terms of NK-mediated lysis could be detected (Celik et al. 2018a), while in the present study where primary dNK cells have been applied, a difference of approx. $45 \%$ in binding efficiency between $H L A$ $G^{*} 01: 01$ and $H L A-G^{*} 01: 03$ could be observed.

Possible explanations for this divergence could be (i) the ability of HLA-G to adapt to the cells where it is expressed (Celik et al. 2018b) and the associated immune functions and/or (ii) a difference in the interacting receptors on the respective immune cells. For inhibiting NK-mediated lysis, ILT2 is the responsible receptor and interaction partner of HLA-G (Shiroishi et al. 2003; Shiroishi et al. 2006). The ILT2/HLA-G interaction is proposed to be mediated mainly through the $\alpha 3$ domain of the HLA-G molecule, although a recent study proposed that the $\alpha 1$ and $\alpha 2$ domains could have also an influence on the ILT2/HLA-G interaction (Nam et al. 2013; Shiroishi et al. 2006). Crystallization studies of KIR2DL2 with HLA-C advocated that KIR binding to HLA molecules is mediated through the $\alpha 1$ and $\alpha 2$ units and the peptide on positions $\mathrm{P} 7$ and $\mathrm{P} 8$ (Boyington et al. 2000). Based on this crystallization study, an equivalent interaction site for KIR2DL4 could be assumed for HLA-G. Still, the concept of HLA-G being a ligand for KIR2DL4 remains highly controversial since a new crystallization study finds no evidence of KIR2DL4 binding HLA-G or other HLA molecules (Moradi et al. 2015). Additionally, the KIR2DL4 receptor misses the D1-D2 arrangement that is proposed to interact with the $\alpha 1$ and $\alpha 2$ domains (Boyington et al. 2000). Despite those findings, it remains evident that only sHLA-G binding could be observed in this study when KIR2DL4 is present on the cell surface indicating that the presence of KIR2DL4 is necessary for binding. Furthermore, the difference in binding of the allelic variants could only be explained by the differences between the three allelic HLA-G variants that cumulate in AA exchanges in the $\alpha 1$ and $\alpha 2$ domains and an altered peptide repertoire (Celik et al. 2018a; Robinson et al. 2014), indicating a KIR family receptor involvement in the form of KIR2DL4 or yet an unknown KIR receptor that is co-expressed with KIR2DL4. Beyond this, it can be proposed that while the interaction of HLA-G with ILT2 is mainly mediated through the $\alpha 3$ domain and only partially influenced by the $\alpha 2$ domain, the binding of the secondary described receptor KIR2DL4 is assumed to be predominantly determined by the $\alpha 1$ and $\alpha 2$ domains and the presented peptide (Figs. 3 and 4). A peptide-mediated alteration of the overall HLA-G structure could presumably lead to a stronger divergence in binding efficiency, and this could be a possible explanation for the differences observed in NK-mediated lysis (Celik et al. 2018a) versus HLA-G/ dNK cell interaction. The presence of an unknown receptor seems to be obvious since the expression levels of KIR2DL4 and ILT2 on the used primary dNK cells revealed expression levels of $\sim 12 \%$ and $\sim 2 \%$, respectively (Fig. 4).

It is proposed that uNK cells start proliferating when incubated with recombinant mHLA-G expressing cells (van der Meer et al. 2004). In the present investigation, the magnitude of allelic HLA-G subtypes on dNK cell proliferation and a possible developmental switch from CD $56^{+ \text {bright }} / \mathrm{CD}^{-}$to $\mathrm{CD} 56^{\text {+bright }} / \mathrm{CD}^{+}$could be identified. The HLA-G allele-dependent proliferative capacity of NK cells from primary placental lymphocytes stands in coherency with the results of the binding efficiency of the allelic sHLA-G subtypes. Proliferation was significantly higher when primary placental NK cells were incubated with K562/mHLA-G*01:04 compared with the other alleles or parental K562 cells. Additionally, $m H L A-G^{*} 01: 01$ promotes a significant stronger proliferation than $m H L A-G^{*} 01: 03$. Furthermore, proliferation is unaffected by the donor's HLA-G genotype, suggesting a more innate character of the interacting receptors for HLA-G. Taken together, this work demonstrates (i) a 
a

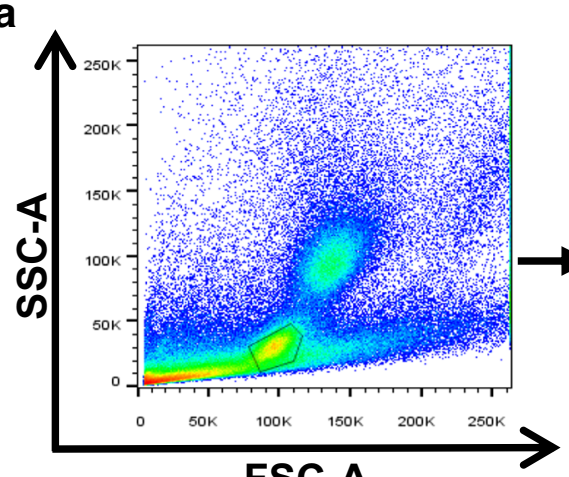

FSC-A

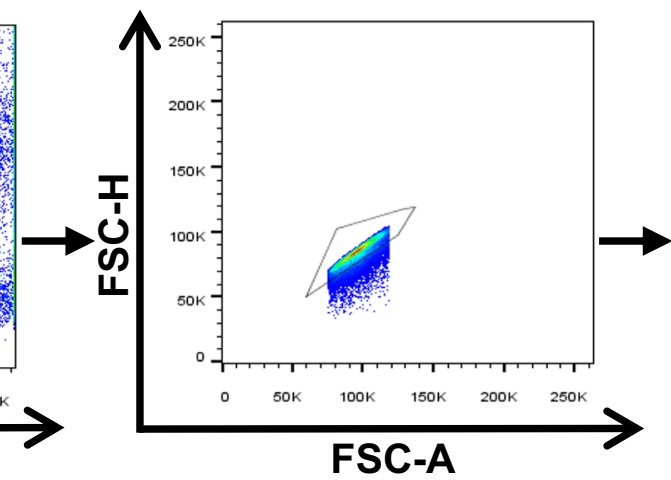

b

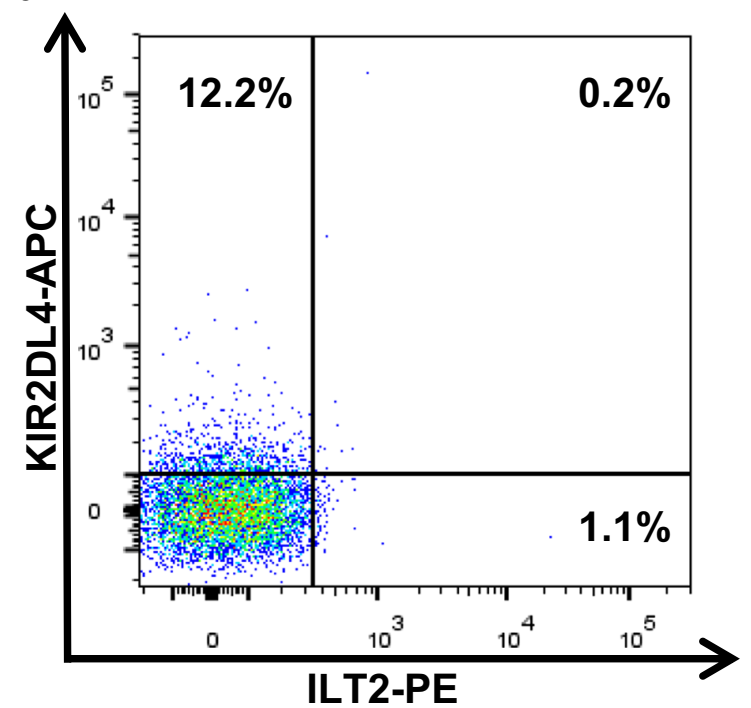

Fig. 4 Expression of KIR2DL4 and ILT2 on primary NK cells from human term placenta. Expression levels of KIR2DL4 and ILT2 on

clear distinction in binding efficiency of the three allelic HLA-G subtypes and (ii) a significant difference in HLA-G allele-mediated proliferation of primary NK cells from human term placenta. In the light of recent studies that tried to generate dNK cells in vitro (Cerdeira et al. 2013) and findings that the sHLA-G level in embryo culture medium correlates with successful pregnancy (Lynge Nilsson et al. 2014), with the overall goal to treat reproductive disorders, this investigation could support those efforts by recommending the allelic variant $H L A-G^{*}$ 01:04 for further use to develop a most efficient treatment.

This work shows the broad functional variability of HLA-G subtypes and implies the need for HLA-G genotyping. Many cellular therapeutic strategies could be supported by the use of synthetic HLA-G and/or by the knowledge about the HLA-G genotype of the patient. Furthermore, the knowledge on HLA-G and its freshly isolated NK cells from human term placenta (b) and gating strategy (a)

biological function appears to be crucial to understand and cure reproductive disorders.

Acknowledgments We thank Marion Haidukiewicz (Department of Obstetrics and Gynecology, Hannover Medical School, Germany) for providing placenta material, and we thank the donors of the placenta for supporting our research.

\section{Compliance with ethical standards}

Conflict of interest The authors declare that they have no conflict of interest.

Open Access This article is distributed under the terms of the Creative Commons Attribution 4.0 International License (http:// creativecommons.org/licenses/by/4.0/), which permits unrestricted use, distribution, and reproduction in any medium, provided you give appropriate credit to the original author(s) and the source, provide a link to the Creative Commons license, and indicate if changes were made. 


\section{References}

Bilinski MJ, Thorne JG, Oh MJ, Leonard S, Murrant C, Tayade C, Croy BA (2008) Uterine NK cells in murine pregnancy. Reprod BioMed Online 16:218-226

Boyington JC, Motyka SA, Schuck P, Brooks AG, Sun PD (2000) Crystal structure of an NK cell immunoglobulin-like receptor in complex with its class I MHC ligand. Nature 405:537-543. https://doi.org/10. $1038 / 35014520$

Carlino C, Stabile H, Morrone S, Bulla R, Soriani A, Agostinis C, Bossi F, Mocci C, Sarazani F, Tedesco F, Santoni A, Gismondi A (2008) Recruitment of circulating NK cells through decidual tissues: a possible mechanism controlling NK cell accumulation in the uterus during early pregnancy. Blood 111:3108-3115. https://doi.org/10. 1182/blood-2007-08-105965

Celik AA, Simper GS, Huyton T, Blasczyk R, Bade-Döding C (2018a) HLA-G mediated immune regulation is impaired by a single amino acid exchange in the alpha 2 domain. Hum Immunol 79:453-462. https://doi.org/10.1016/j.humimm.2018.03.010

Celik AA, Simper GS, Hiemisch W, Blasczyk R, Bade-Döding C (2018b) HLA-G peptide preferences change in transformed cells: impact on the binding motif. Immunogenetics 70:485-494. https://doi.org/10. 1007/s00251-018-1058-2

Cerdeira AS, Rajakumar A, Royle CM, Lo A, Husain Z, Thadhani RI, Sukhatme VP, Karumanchi SA, Kopcow HD (2013) Conversion of peripheral blood NK cells to a decidual NK-like phenotype by a cocktail of defined factors. J Immunol 190:3939-3948. https://doi. org/10.4049/jimmunol.1202582

Drake PM, Gunn MD, Charo IF, Tsou CL, Zhou Y, Huang L, Fisher SJ (2001) Human placental cytotrophoblasts attract monocytes and CD56(bright) natural killer cells via the actions of monocyte inflammatory protein 1alpha. J Exp Med 193:1199-1212

Ferreira LMR, Meissner TB, Tilburgs T, Strominger JL (2017) HLA-G: at the interface of maternal-fetal tolerance. Trends Immunol 38:272 286. https://doi.org/10.1016/j.it.2017.01.009

Fournel S, Aguerre-Girr M, Huc X, Lenfant F, Alam A, Toubert A, Bensussan A, Le Bouteiller P (2000) Cutting edge: soluble HLAG1 triggers CD95/CD95 ligand-mediated apoptosis in activated CD8+ cells by interacting with CD8. J Immunol 164:6100-6104

Hanna J, Wald O, Goldman-Wohl D, Prus D, Markel G, Gazit R, Katz G, Haimov-Kochman R, Fujii N, Yagel S, Peled A, Mandelboim O (2003) CXCL12 expression by invasive trophoblasts induces the specific migration of CD16-human natural killer cells. Blood 102: 1569-1577. https://doi.org/10.1182/blood-2003-02-0517

Hazan AD, Smith SD, Jones RL, Whittle W, Lye SJ, Dunk CE (2010) Vascular-leukocyte interactions. mechanisms of human decidual spiral artery remodeling in vitro Am J Pathol 177:1017-1030. https://doi.org/10.2353/ajpath.2010.091105

Jabrane-Ferrat N, Siewiera J (2014) The up side of decidual natural killer cells: new developments in immunology of pregnancy. Immunology 141:490-497. https://doi.org/10.1111/imm.12218

Jost S, Altfeld M (2013) Control of human viral infections by natural killer cells. Annu Rev Immunol 31:163-194. https://doi.org/10. 1146/annurev-immunol-032712-100001

Juch H, Blaschitz A, Dohr G, Hutter H (2012) HLA class I expression in the human placenta. Wien Med Wochenschr 162:196-200. https:// doi.org/10.1007/s10354-012-0070-7

Kane N, Kelly R, Saunders PTK, Critchley HOD (2009) Proliferation of uterine natural killer cells is induced by human chorionic gonadotropin and mediated via the mannose receptor. Endocrinology 150: 2882-2888. https://doi.org/10.1210/en.2008-1309

King A, Wellings V, Gardner L, Loke YW (1989) Immunocytochemical characterization of the unusual large granular lymphocytes in human endometrium throughout the menstrual cycle. Hum Immunol 24: 195-205. https://doi.org/10.1016/0198-8859(89)90060-8
Koopman LA, Kopcow HD, Rybalov B, Boyson JE, Orange JS, Schatz F, Masch R, Lockwood CJ, Schachter AD, Park PJ, Strominger JL (2003) Human decidual natural killer cells are a unique NK cell subset with immunomodulatory potential. J Exp Med 198:12011212. https://doi.org/10.1084/jem.20030305

Kopcow HD, Allan DSJ, Chen X, Rybalov B, Andzelm MM, Ge B, Strominger JL (2005) Human decidual NK cells form immature activating synapses and are not cytotoxic. Proc Natl Acad Sci U S A 102:15563-15568. https://doi.org/10.1073/pnas.0507835102

Kunkel EJ, Butcher EC (2002) Chemokines and the tissue-specific migration of lymphocytes. Immunity 16:1-4

Le Bouteiller P (2013) Human decidual NK cells: unique and tightly regulated effector functions in healthy and pathogen-infected pregnancies. Front Immunol 4. https://doi.org/10.3389/fimmu.2013. 00404

Lyall F, Bulmer JN, Duffie E, Cousins F, Theriault A, Robson SC (2001) Human trophoblast invasion and spiral artery transformation. Am J Pathol 158:1713-1721. https://doi.org/10.1016/S0002-9440(10) 64127-2

Lynge Nilsson L, Djurisic S, Hviid TVF (2014) Controlling the immunological crosstalk during conception and pregnancy: HLA-G in reproduction. Front Immunol 5:198. https://doi.org/10.3389/ fimmu.2014.00198

Manaster I, Mandelboim O (2008) The unique properties of human NK cells in the uterine mucosa. Placenta 29(Suppl A:S60-6):60-66. https://doi.org/10.1016/j.placenta.2007.10.006

Moffett-King A (2002) Natural killer cells and pregnancy. Nat Rev Immunol 2:656-663. https://doi.org/10.1038/nri886

Moradi S, Berry R, Pymm P, Hitchen C, Beckham SA, Wilce MCJ, Walpole NG, Clements CS, Reid HH, Perugini MA, Brooks AG, Rossjohn J, Vivian JP (2015) The structure of the atypical killer cell immunoglobulin-like receptor, KIR2DL4. J Biol Chem 290:10460 10471. https://doi.org/10.1074/jbc.M114.612291

Nam G, Shi Y, Ryu M, Wang Q, Song H, Liu J, Yan J, Qi J, Gao GF (2013) Crystal structures of the two membrane-proximal Ig-like domains (D3D4) of LILRB1/B2: alternative models for their involvement in peptide-HLA binding. Protein Cell 4:761-770. https://doi. org/10.1007/s13238-013-3908-x

Quack KC, Vassiliadou N, Pudney J, Anderson DJ, Hill JA (2001) Leukocyte activation in the decidua of chromosomally normal and abnormal fetuses from women with recurrent abortion. Hum Reprod 16:949-955

Robinson J, Halliwell JA, Hayhurst JD, Flicek P, Parham P, Marsh SGE (2014) The IPD and IMGT/HLA database: allele variant databases. Nucleic Acids Res 43:D423-D431. https://doi.org/10.1093/nar/ gku1161

Robson A, Harris LK, Innes BA, Lash GE, Aljunaidy MM, Aplin JD, Baker PN, Robson SC, Bulmer JN (2012) Uterine natural killer cells initiate spiral artery remodeling in human pregnancy. FASEB J 26: 4876-4885. https://doi.org/10.1096/fj.12-210310

Shiroishi M, Tsumoto K, Amano K, Shirakihara Y, Colonna M, Braud VM, Allan DSJ, Makadzange A, Rowland-Jones S, Willcox B, Jones EY, van der Merwe PA, Kumagai I, Maenaka K (2003) Human inhibitory receptors Ig-like transcript 2 (ILT2) and ILT4 compete with $\mathrm{CD} 8$ for MHC class I binding and bind preferentially to HLA-G. Proc Natl Acad Sci U S A 100:8856-8861. https://doi. org/10.1073/pnas.1431057100

Shiroishi M, Kuroki K, Rasubala L, Tsumoto K, Kumagai I, Kurimoto E, Kato K, Kohda D, Maenaka K (2006) Structural basis for recognition of the nonclassical MHC molecule HLA-G by the leukocyte Iglike receptor B2 (LILRB2/LIR2/ILT4/CD85d). Proc Natl Acad Sci U S A 103:16412-16417. https://doi.org/10.1073/pnas.0605228103

Smith SD, Dunk CE, Aplin JD, Harris LK, Jones RL (2009) Evidence for immune cell involvement in decidual spiral arteriole remodeling in early human pregnancy. Am J Pathol 174:1959-1971. https://doi. org/10.2353/ajpath.2009.080995 
Tilburgs T, Evans JH, Crespo ÂC, Strominger JL (2015) The HLA-G cycle provides for both NK tolerance and immunity at the maternalfetal interface. Proc Natl Acad Sci U S A 112:13312-13317. https:// doi.org/10.1073/pnas.1517724112

Timonen T, Ortaldo HRB (1981) Characteristics of human large granular lymphocytes and relationship to natural killer and $\mathrm{K}$ cells. J Exp Med 153:569-582

Toni Ho G-G, Heinen F, Stieglitz F, Blasczyk R, Bade-Döding C (2018) Dynamic interaction between immune escape mechanism and HLAIb regulation. In: immunogenetics [working title]. IntechOpen

Vacca P, Cantoni C, Vitale M, Prato C, Canegallo F, Fenoglio D, Ragni N, Moretta L, Mingari MC (2010) Crosstalk between decidual NK and CD14+ myelomonocytic cells results in induction of Tregs and immunosuppression. Proc Natl Acad Sci U S A 107:11918-11923. https://doi.org/10.1073/pnas.1001749107
Vacca P, Moretta L, Moretta A, Mingari MC (2011) Origin, phenotype and function of human natural killer cells in pregnancy. Trends Immunol 32:517-523. https://doi.org/10.1016/j.it.2011.06.013

van der Meer A, Lukassen HGM, van Lierop MJC, Wijnands F, Mosselman S, Braat DDM, Joosten I (2004) Membrane-bound HLA-G activates proliferation and interferon-gamma production by uterine natural killer cells. Mol Hum Reprod 10:189-195. https://doi.org/10.1093/molehr/gah032

Publisher's note Springer Nature remains neutral with regard to jurisdictional claims in published maps and institutional affiliations. 